\title{
Upper Gastrointestinal Endoscopy at University Hospital Souro Sanou Bobo-Dioulasso (Burkina Faso), about 1022 Cases: Signs and Lesions Observed
}

\author{
Mâli Koura', Delphine Passolguewindé Zongo Napon'ㄹ, Zanga Damien Ouattara ${ }^{2}$, \\ Kounpiélimé Sosthène Somda ${ }^{3}$, Aboubacar Coulibaly3 ${ }^{3}$, Steve Léonce Zoungrana ${ }^{2}$, \\ Christine Couna Somé Bere ${ }^{4}$, Sandrine Hema Soudré5, Euloges Bébar Kamboulé1, \\ Nogogna Zouré1, Honoré Zougmoré1, Inoussa Adama Zampou1, Appolinaire Sawadogo1
}

\author{
${ }^{1}$ Gastroenterology Service of the University Hospital Souro Sanou, Bobo-Dioulasso, Burkina Faso \\ ${ }^{2}$ Regional University Hospital of Ouahigouya, Ouahigouya, Burkina Faso \\ ${ }^{3}$ Gastroenterology Service of the University Hospital Yalgado Ouédraogo, Ouagadougou, Burkina Faso \\ ${ }^{4}$ Regional Hospital Kaya, Kaya, Burkina Faso \\ ${ }^{5}$ National Hospital Blaise Compaoré, Ouagadougou, Burkina Faso \\ Email:kouramali@yahoo.fr
}

How to cite this paper: Koura, M., Napon, D.P.Z., Ouattara, Z.D., Somda, K.S., Coulibaly, A., Zoungrana, S.L., Bere, C.C.S., Soudré, S.H., Kamboulé, E.B., Zouré, N., Zougmoré, H., Zampou, I.A. and Sawadogo, A. (2017) Upper Gastrointestinal Endoscopy at University Hospital Souro Sanou Bobo-Dioulasso (Burkina Faso), about 1022 Cases: Signs and Lesions Observed. Open Journal of Gastroenterology, 7, 287-296.

https://doi.org/10.4236/ojgas.2017.711030

Received: October 6, 2017

Accepted: November 24, 2017

Published: November 27, 2017

Copyright $(9) 2017$ by authors and Scientific Research Publishing Inc. This work is licensed under the Creative Commons Attribution International License (CC BY 4.0).

http://creativecommons.org/licenses/by/4.0/ c) (i) Open Access

\begin{abstract}
Upper gastrointestinal endoscopy is an excellent way for the diagnosis of high digestive pathology. We report the results of 1022 upper gastrointestinal endoscopy performed at Bobo-Dioulasso CHU-SS, in western Burkina Faso (West Africa). The aim of this study was to document the indications and lesions found in high endoscopy at the CHUSS. Patients and Methods: It was a cross-sectional study, prospective to describe the results of gastroscopy performed from 1st January 2015 to 30th June 2016 at the digestive endoscopy unit CHU-Souro Sanou Bobo-Dioulasso. Results: In the study period, 1022 upper gastrointestinal endoscopies were performed. The main indications were: The epigastric pain (48.6\%), portal hypertension (10.7\%) and gastroesophageal reflux disease $(9.9 \%)$. The pathologies observed were dominated by gastropathies $(48.11 \%)$, peptic ulcer $(27 \%)$ and oesophageal varices $(9.68 \%)$. Epigastralgias were the main circumstance for the discovery of: $52.3 \%$ of esophagitis, $49.17 \%$ of gastropathies and $46.12 \%$ of peptic ulcers. Histopathologically, the results of the 236 biopsies were dominated by gastritis $(88.56 \%)$, stomach cancers (7.63\%) and esophagus (3.81\%). Conclusion: The main indication of the UGIE at the CHU-Souro Sanou in Bobo-Dioulasso was epigastralgia. The pathologies observed were dominated by gastropathy, esophagitis and PUD.
\end{abstract}




\section{Keywords}

Upper Gastrointestinal Endoscopic, Indications, Lesions Observed, Bobo-Dioulasso

\section{Introduction}

The upper gastrointestinal endoscopy (UGIE) is a test that allows to visualize the interior of the esophagus, stomach, duodenum and the mucous membrane lining them. Morphological examination for the exploration of the upper digestive tract is performed in an aetiological purpose, or therapy.

Common practice in developed countries, is still a luxury in our countries with limited income. In fact, in our countries in the south of the Sahara, there is the problem of its technical, geographical and financial accessibility. In Africa, many studies have been made on the indications and results in endoscopy [1]-[15]. In Burkina Faso, no similar publication has yet appeared. It therefore seemed justified for us to report indications and results of 1022 endoscopies performed in 17 months in a hospital in resource-limited countries.

The purpose of this study was to document indications and lesions found in high endoscopic in CHUSS.

\section{Patients and Methods}

\subsection{Type of Study, Population and Sampling}

This was a cross-sectional, prospective, descriptive study carried out from 1st January 2015 to 30th June 2016 in the digestive endoscopy unit of the Hepato-Gastroenterology Department of the University Hospital Souro Sanou (CHU-SS) in Bobo-Dioulasso (Burkina Faso). The patients in the sample were included in the study as they arrived at the endoscopy unit. CHU-SS is the reference center of four health regions (Mouhoun, Cascades, Hauts Bassins and South-west) of the western half of Burkina whose population is estimated to $5,156,289$ inhabitants [16] and $28.8 \%$ of the population of Burkina Faso. The protocol was approved by the hospital ethics committee of CHU-SS. Were included in this study all patients from both rural and urban areas who underwent upper gastrointestinal endoscopy during the study period.

\subsection{Variables and Data Collection Technique}

The data collected concerned the socio-demographic characteristics of the patients, the main indication and the result of UGIE. All reports of UGIE were included. Biopsies for histology were systematic in all lesions of gastritis and dysmitoses, and in each case for other injuries. No staining was done.

The various endoscopic examinations were performed in the endoscopy unit by a gastroenterologist assisted by an aide. The exploration technique was classic. The apparatus used was a brand video-endoscope STORZ 13821 PKS with a 
multidirectional probe axially vision. All patients were previously submitted to a local anesthesia to viscous Xylocaine $2 \%$. No general anesthesia was performed.

\subsection{Data Processing and Analysis}

The data collected was captured and analyzed using SPSS software version 20. Descriptive statistics were used to determine the average and standard deviations of the quantitative variables as well as the proportions of the various afflictions.

\subsection{Operational Definitions}

- Inflammatory lesions grouped the esophagitis (including esophageal ulcers), the gastropathies (gastritis) and duodenitis.

- The diagnosis of mycotic esophagitis was based on endoscopic lesions type Candida albicans [13].

- The term "dysmitose" means any suspicious new formation of malignancy in endoscopic.

- Gastro-esophageal reflux disease (GERD), consisted heartburn, regurgitations and retro-sternal pain [17].

\section{Results}

\subsection{Demographic of Patients}

In this study, 1022 patients were included. Table 1 presents the socio-demographic characteristics of our sample. There were 552 women (54\%) and 470 men (46\%). The average age was $41.72[ \pm 15.59]$ years with extremes of 7 and 85 years. The median age was 40 and $75 \%$ had more than 53 years.

The stomach and duodenum were examined in respectively 1006 and 1000 patients due to non crossed esophageal stenosis $(n=16)$ and/or antrum-pyloric $(\mathrm{n}=6)$.

\subsection{Indications of an Upper Gastrointestinal Endoscopy (UGIE)}

For the whole sample, the endoscopic examination was performed in almost half of cases (48.6\%) for epigastralgia. Then follow, the search for signs of portal hypertension (10.7\%), gastroesophageal reflux disease (9.9\%), gastrointestinal bleeding (8\%) and dysphagia (4.4\%). Table 2 summarizes the various indications of the OGDE during our study.

\subsection{The Lesions Observed in the Upper Gastrointestinal Endoscopy}

Endoscopic Examination was abnormal in $86.7 \%$ (886) of our patients. Among them, more than the half $(51.02 \%)$ were more than 40 years old.

The achievement was multi-organic with 358 (40.41\%) patients. It was the double with 302 patients and the triple with 56 patients. The achievement was especially gastric and concerned $61.93 \%$ (623) patients, followed by that of the esophagus and duodenum respectively at $41 \%$ (419) and $22.32 \%$ (223) patients 
Table 1. Demographics of 1022 patients.

\begin{tabular}{cccc}
\hline & & Enrollment (\%) & Cumulative headcount (\%) \\
\hline Gender & Male & $470(46)$ & $470(46)$ \\
Age* & Female & $552(54)$ & $1022(100)$ \\
& & 42,636 & $41.72 \pm 15.59$ \\
& {$[7-14]$} & $11(1.07)$ & $11(1.07)$ \\
Age group & {$[15-20]$} & $62(6.07)$ & $73(7.14)$ \\
(years) & {$[21-30]$} & $209(20.45)$ & $282(27.59)$ \\
& {$[31-40]$} & $243(23.78)$ & $525(51.37)$ \\
& {$[41-50]$} & $209(20.45)$ & $734(71.82)$ \\
& {$[51-60]$} & $153(14.97)$ & $887(86.79)$ \\
& {$[61-70]$} & $92(9.00)$ & $1022(100)$ \\
\hline
\end{tabular}

*: Expressed on average \pm standard deviation.

Table 2. The different indications of UGIE at CHU-SS in Bobo-Dioulasso.

\begin{tabular}{|c|c|c|}
\hline Indications & Numbers (n) & Percentages (\%) \\
\hline Epigastric pain & 497 & 48.6 \\
\hline Search for HTP & 109 & 10.6 \\
\hline GERD & 101 & 9.9 \\
\hline Upper gastrointestinal bleeding & 88 & 8.6 \\
\hline Dysphagia & 45 & 4.4 \\
\hline Vomiting & 41 & 4 \\
\hline Dyspepsia & 27 & 2.6 \\
\hline Stomach operated control* & 26 & 2.5 \\
\hline PUD control & 19 & 1.9 \\
\hline Anemia & 17 & 1.7 \\
\hline Suspicion of gastric tumor & 14 & 1.4 \\
\hline Caustic burn & 11 & 1.1 \\
\hline Other abdominal pain & 10 & 1.0 \\
\hline Halitosis & 06 & 0.6 \\
\hline Chronic gastritis & 04 & 0.4 \\
\hline Various & 07 & 0.7 \\
\hline Total & 1022 & 100 \\
\hline
\end{tabular}

*: Stomach surgery for ulcer complications (2.3\%) and gastric tumor (0.2\%).

(Table 3). We observed a predominance of inflammatory lesions (63.22\%). A total of 1412 lesions (Table 3) was observed during our study including 38.38\% of gastropathy, $19.19 \%$ of peptic ulcer and $16.64 \%$ of reflux esophagitis. Note 
Table 3. Topographic distribution of different lesions observed in UGIE.

\begin{tabular}{|c|c|c|c|c|}
\hline & Observed lesions & $\begin{array}{l}\text { Number of } \\
\text { lesions }\end{array}$ & $\begin{array}{l}\text { Percentage } \\
\text { of lesion }\end{array}$ & $\begin{array}{l}\text { Endoscopic } \\
\text { prevalence }\end{array}$ \\
\hline & Peptic esophagitis & 235 & 16.64 & 22.99 \\
\hline & Mycotic oesophagitis & 59 & 4.18 & 5.77 \\
\hline & Caustic esophagitis & 9 & 0.64 & 0.88 \\
\hline & Other esophagitis & 4 & 0.28 & 0.39 \\
\hline & Oesophageal ulcer & 15 & 1.06 & 1.47 \\
\hline & Oesophageal dysmitosis & 14 & 1.00 & 1.37 \\
\hline \multirow[t]{10}{*}{ Esophagus } & Polyp & 4 & 0.28 & 0.39 \\
\hline & Varicose veins & 99 & 7.01 & 9.68 \\
\hline & Stenosis & 18 & 1.28 & 1.76 \\
\hline & Mega-esophagus & 3 & 0.21 & 0.30 \\
\hline & Constrictions upper $1 / 3$ & 1 & 0.07 & 0.10 \\
\hline & Diverticulum & 1 & 0.07 & 0.10 \\
\hline & Total oesophageal lesions & 462 & 32.72 & 41 \\
\hline & gastropathie & 542 & 38.38 & 48.11 \\
\hline & Gastric Ulcer (UG) & 172 & 12.18 & 17.10 \\
\hline & Gastric dysmitosis & 23 & 1.63 & 2.29 \\
\hline \multirow[t]{7}{*}{ Stomach } & polyps & 4 & 0.28 & 0.40 \\
\hline & gastroparesis & 7 & 0.50 & 0.69 \\
\hline & Antro-pyloric stenosis & 7 & 0.50 & 0.69 \\
\hline & Total gastric lesions & 755 & 53.47 & 61.93 \\
\hline & Duodenal ulcer (DU) & 99 & 7.01 & 9.91 \\
\hline & Duodenopathie & 53 & 3.75 & 5.30 \\
\hline & Biliary duodeno-gastric reflux & 33 & 2.34 & 3.30 \\
\hline \multirow[t]{4}{*}{ Duodenum } & Bulbar-duodenal stenosis & 7 & 0.50 & 0.70 \\
\hline & Duodenal polyp & 2 & 0.14 & 0.20 \\
\hline & $\begin{array}{l}\text { Dysmitosis of the } \\
\text { duodenal papilla }\end{array}$ & 1 & 0.07 & 0.10 \\
\hline & Total duodenal lesions & 195 & 13.81 & 19.81 \\
\hline \multicolumn{2}{|c|}{ Total observed lesions } & 1412 & 100 & \\
\hline
\end{tabular}

that gastropathies and peptic ulcer disease (PUD) were reported respectively in $484(48.11 \%)$ and $271(27 \%)$ patients, of the patients examined by UGIE. As other lesions observed, it was esophageal varices of the stomach and esophagus dysmitoses reported respectively at $9.68 \%, 2.29 \%$ and $1.37 \%$ of our patients.

Depending on the indication of UGIE (Table 4), the epigatralgies were the main circumstance of peptic esophagitis discovery (52.3\%) of gastropathies (49.17\%) and PUD (46.12\%) in our patients. Portal hypertension was the major factor in the demonstration of $62.63 \%$ of esophageal varices (VO). The main 
Table 4. Distribution of main lesions observed by major indication of UGIE.

\begin{tabular}{cccccccc}
\hline & Gastropathy & PUD & $\begin{array}{c}\text { Peptic } \\
\text { esophagitis }\end{array}$ & VO & $\begin{array}{c}\text { Oesophageal } \\
\text { candidiasis }\end{array}$ & $\begin{array}{c}\text { Gastric } \\
\text { cancer }\end{array}$ & $\begin{array}{c}\text { Oesophageal } \\
\text { cancer }\end{array}$ \\
\cline { 2 - 7 } & $\mathrm{n}(\%)$ & $\mathrm{n}(\%)$ & $\mathrm{n}(\%)$ & $\mathrm{n}(\%)$ & $\mathrm{n}(\%)$ & $\mathrm{n}(\%)$ & $\mathrm{n}(\%)$ \\
\hline $\begin{array}{c}\text { Epigastric } \\
\text { pain }\end{array}$ & 238 & 125 & 123 & 14 & 24 & 2 & 2 \\
Search for & 67 & 32 & 10 & 62 & 7 & 1 & 0 \\
HTP & $(13.84)$ & $(11.80)$ & $(4.2)$ & $(62.63)$ & $(11.86)$ & $(4.35)$ & $(0.00)$ \\
GERD & 50 & 16 & 37 & 2 & 7 & 0 & 0 \\
UGI & $(10.33)$ & $(5.90)$ & $(15.74)$ & $(2.02)$ & $(11.86)$ & $(0.0)$ & $(0.0)$ \\
bleeding & 31 & 51 & 13 & 18 & 6 & 6 & 3 \\
Dysphagia & $(6.40)$ & $(18.82)$ & $(5.53)$ & $(18.18)$ & $(10.17)$ & $(26.09)$ & $(21.42)$ \\
& $(4.13)$ & $(1.48)$ & $(6.4)$ & 0 & 7 & $00.04)$ & 8 \\
Vomiting & 18 & 10 & & $(0.0)$ & $(11.86)$ & & $(57.14)$ \\
Dyspepsia & $(3.72)$ & $(3.69)$ & $(4.25)$ & 0 & 2 & 3 & 1 \\
& 14 & 4 & & $(0.0)$ & $(3.39)$ & $(13.04)$ & $(7.14)$ \\
& $(2.89)$ & $(1.48)$ & $(4.25)$ & 0 & 0 & 0 & 0 \\
\end{tabular}

lesions observed in the GER syndrome were especially peptic esophagitis (15.74\%) and fungal (11.86\%). Upper gastrointestinal bleeding was a diagnostic circumstance of $18.82 \%$ of PUD and $18.18 \%$ of VO (Table 3). Dysphagia was the circumstance of diagnosis for $57.14 \%$ of esophageal dysmitoses and $11.86 \%$ of esophageal mycosis.

Histologically, only $53.88 \%$ (236) of the results of our various biopsies (438) were available. It was: 209 (88.56\%) cases of gastritis which $192(91.87 \%)$ cases of chronic gastritis; 17 cases of gastric adenocarcinoma and 1 case of gastrointestinal stromal tumor (GIST). In esophageal level 8 cases of adenocarcinoma and one case of carcinoma in situ, and 1 case subacute oesophagitis is diagnosed. In the duodenum, one case of adenocarcinoma papilla duodenal and 1 case of subacute duodenitis were reported.

\section{Discussion}

In our study the epigastric pains were the main indication (48.6\%) of UGIE. This is a constant indication of UGIE which is also reported in the literature [3] [6] [7] [8] [9] [11] [18] [19]. The frequency of epigastric pains in our study is close to that of several other authors [6] [9] [11], but remained higher than that of others [1] [3] [7] [8] [18] respectively related frequencies between $30.2 \%$ and $43.5 \%$. It remains below the $60.68 \%$ reported by Lawson-Ananissoh L.M. [9] in Lomé, to $58.9 \%$ of Stephen in Ghana, and $72.9 \%$ of Peghini M. [20] Antananarivo. These differences may be related to the difficulty some patients meet to characterize their painful symptoms. Similarly, the type of endoscopic lesions observed in different series could explain this variability in the frequency of this indication. Other indications of UGIE in our study were HTP, GERD, digestive bleeding and dysphagia. The research of portal hypertension signs was a rare indication of some authors [8] [11] who reported that between $0.22 \%$ and $1.33 \%$. 
Our result was higher than those of other authors [5] [9] who reported frequencies of $5.9 \%$ and $6.97 \%$, but remained near the $10.8 \%$ of Taye [14] in Ethiopia. Attia Y. [1] in Abidjan brought back a frequency at $15.75 \%$ of this indication. This is actually a particular indication, which depends more on the practitioner and the patient's complaint. In our series, the relative high frequency $(10.7 \%)$ of this indication was related to the classical indications (before clinical or endoscopic signs of HPT), as well as its systematic indication before a chronic viral liver disease B or C. GERD represented 9.9\% indications of UGIE in our study. This frequency is close to those of other authors [6] [8] [11] [19] who reported results varying between $8.9 \%$ and $9.8 \%$. RGO in our study was 1.6 times higher than in Fasla H. [3] and Peghini [20], but remained far ahead of those of other authors [4] [9] [21] [22]. In Congo, Ibara JR [5] reported 20.1\% of indications for RGO. The low frequency observed for this indication in some studies, seems not to be related to a real weakness of its frequency but probably related to the content of the definition of RGO in view of the high prevalence of dyspepsia in some series [4] [7] [12] [18] [22].

Digestive hemorrhage was an indication of UGIE in $8 \%$ of our patients. Similar frequencies are reported by other authors [6] [9] [11] [19] [20] [22]. Other frequencies higher between $11.29 \%$ and $26.2 \%$ were observed in other series [3] [7] [8] [12] [14] [18] [21]. Gyedu A [4] reported a frequency of $1.7 \%$ in Kumasi in Ghana. The gastrointestinal bleeding remains a fairly constant indication in the different series of endoscopies. The frequency differences could be related to the characteristics of each population studied (age), the associated risk factors and the type of endoscopic lesions. Indeed, on the one hand, some of its etiologies remain frequent, including PUD, esophageal varices observed in chronic hepatopathies with HTP and acute mucosal lesions due to the use of NSAIDs (non-steroidal anti-inflammatory drugs). On the other hand, population aging increases the number of patients on aspirin and other long-term NSAIDs. The latter are medicines taken most often in self-medication, a common practice in many cities.

Dysphagia was the indication of endoscopy in $4.4 \%$ of patients. Similar values are reported in other series [11] [12] [21]. Similarly our values are close to $6.3 \%$ of Fasla H. [3] and 6.4\% of Tabiri S. [19]. Dysphagia appeared as a rare indication of UGIE, according to some authors [4] [9] [18] [22] who reported between $1 \%$ and $2.2 \%$. Ismaila $\mathrm{BO}$, in Nigeria [6] reported a rate of $10.7 \%$ for dysphagia among the indications. Variations of this indication are related to the epidemiology of causal diseases. Dysphagia is a late sign of certain neoplasias. In developing countries, late consultation might explain its relative frequency.

We had observed at the upper digestive tract, a predominance of inflammatory pathology (64.94\%) at endoscopy. This predominance of the inflammatory pathology was confirmed histologically which reported that $89.41 \%$ of the parts of biopsies. It was dominated by gastritis $(88.56 \%)$. This same observation is made by the majority of African authors [3] [4] [5] [6] [11] [12]. This predomi- 
nant gastritis with inflammatory dominance in our study can be explained by the widespread use of anti-inflammatory drugs for self-medication, frequent intestinal parasites in our context, alcohol, and duodenal-gastric bile reflux. While stressing the descent of the inflammatory pathology, some African authors [9] [18] [19] reported a predominance of the PUD. Tunc M. Turkey [22] instead reported a prevalence of PUD far ahead of inflammatory pathology.

In our study, the disease PUD was present in 27\% (271) of patients examined. Our results are close to those of other authors [8] [11] [18] which reported prevalences between $22.8 \%$ and $31.65 \%$. Our prevalence is higher than those of other series [1] [4] [6] [9] [12], but remains well below the $33.5 \%$ to $47.5 \%$ reported by other authors [5] [7] [19] [20] [22]. We found that the ulcer was 1.69 times more localized in the stomach and in the duodenum in our study. This is in contradiction with the literature and with the results of a number of authors [1] [5] [7] [8] [9] [11] [18] [20]. Our results are similar to those of other Burkinabe authors [2] [10] [15] and West Africans [4] [19]. Similarly, Tunc M. [22] in Turkey noted a prevalence of gastric ulcer localization.

The esophageal varices were present in $9.68 \%$ of our patients. Lower prevalences, ranging from $1.2 \%$ to $6.39 \%$ are reported by some African authors [4] [5] [6] [9] [11] [12] and Turkish [22]. Our value is, however, close to that of Attia [1] in Ivory Coast which reported $8.5 \%$ of esophageal varices. The high incidence of cirrhosis and liver cancer in our context could be an explanation. Our technical platforms are limited for the curative treatment of liver cancers; one of the palliative alternatives is to take care of the complications in order to lengthen if possible the survival of the patients.

The dysmitoses of the upper digestive tract were reported in 3.76\% ( $n=38)$ of patients examined. It was histologically $18(1.79 \%)$ cases of gastric cancer that predominated and $9(0.88 \%)$ cases of esophageal cancer. This predominance of gastric cancer among cancers of the upper digestive tract is also reported by many authors [4] [5] [7] [9] [11] [12] [18] [19] [22] with prevalence included between $0.92 \%$ and $6.7 \%$. Other authors reported rather, a predominance of esophageal cancer [6] [8]. These results show that upper gastrointestinal cancers and stomach cancer are no longer rare in Africa. Indeed, the increasing availability of populations with endoscopic examinations predicts a number of cases in subsequent years. Risk factors are also more frequent with globalization: Smoking, alcoholism, excessive consumption of red meat, too salty and too greasy food.

The epigastric pains were our main discovery circumstance of: Reflux esophagitis, the gastropathie and the PUD. This same observation was made by Kodjoh $\mathrm{N}$ [8] in Benin who reported $41.7 \%$ of esophagitis, $37.7 \%$ of gastritis and $28.9 \%$ of PUD discovered after this indication. This is explained by the fact that the epigastric pains were in our two series the main symptom reported by patients. It is a common symptom in both digestive pathologies and heart disease.

\section{Conclusion}

This study shows that the epigastric pain was the main indication of UGIE with 
patients received in the digestive endoscopy unit at CHU-SS. Pathologies observed were dominated by gastritis, the esophagitis and PUD disease. On the other hand, is there an emergence of cancers of the stomach and the esophagus?

\section{Conflict of Interest}

The authors state not to have conflict of interest.

\section{References}

[1] Attia, Y., Gaudet, D., Manlan, K. and Carsuzaa, M. (1981) 15-Month Review of Upper Digestive Endoscopy at Cocody University Hospital. Medical Journal of Côte d'Ivoire, 54, 16-22.

[2] Coulibaly, A., Sermé, A.K., Godonou, H., Somda, K.S., Cissé, K., Sia, R., Kafando, R., Sombie, R.A. and Bougouma, A. (2016) Peptic Ulcer Disease in CHUYO. Open Journal of Gastroenterology, 6, 353-361. https://doi.org/10.4236/ojgas.2016.611038

[3] Fasla, H. and Krati, K.K. (2007) Annual Review of the Digestive Endoscopy Unit from the CHU Med VI (2004-2008). Thesis $n^{\circ} 77$, Faculty of Medicine and Pharmacy, Marrakech.

[4] Gyedu, A. and Yorke, J. (2014) Upper Gastrointestinal Endoscopy in the Patient Population of Kumasi, Ghana: Indications and Findings. Pan African Medical Journal, 18, 327. https://doi.org/10.11604/pamj.2014.18.327.4806

[5] Ibara, J.R., Moukassa, B. and Itoua-Ngaporo, A. (1993) La pathologie digestive haute au Congo à propos de 2393 endoscopies réalisées au C.H.U de Brazzaville. [The Upper Digestive Pathology in Congo about 2393 Endoscopies Conducted in CH U Brazzaville.] Medicine of Black Africa, 40.

[6] Ismaila, B.O. and Misauno, M.A. (2013) Gastrointestinal Endoscopy in Nigeria: A Prospective Two Year Audit. Pan African Medical Journal, 14, 22.

https://doi.org/10.11604/pamj.2013.14.22.1865

[7] Jeje, E., Olajide, T. and Akande, B. (2013) Upper Gastrointestinal Endoscopy-Our Findings, Our Experience in Lagoon Hospital, Lagos, Nigeria. Macedonian Journal of Medical Sciences, 6, 168-173.

[8] Kodjoh, N., Hountondji, A. and Addra, B. (1992) Apport de l'endoscopie au diagnostic des affections œsogastroduodénales en milieu tropical: expérience Béninoise à propos de 930 examens. [Intake of Endoscopy to Diagnose Oesogastroduodenal Conditions in the Tropics: Experience in Benin about 930 Exams.] Medicine of Black Africa, 39, 36-44.

[9] Lawson-Ananissoh, L.M., Bouglouga, O., Bagny, A., Kaaga, L. and Redah, D. (2014) La fibroscopie digestive haute chez 2795 patients au centre hospitalier universitaire-campus de Lomé : les particularités selon le sexe. [The High Digestive Fibroscopy in 2795 Patients at the University Hospital-Lomé Campus: Characteristics by Sex.] Pan African Medical Journal, 19, 262. https://doi.org/10.11604/pamj.2014.19.262.4512

[10] Millogo, T. (2010) Maladie ulcéreuse gastro-duodénale en hospitalisation au CHU/YO: Aspects épidémiologiques, cliniques et thérapeutiques. [Gastroduodenal Ulcer Disease in Hospitalization at CHU/YO: Epidemiological, Clinical and Therapeutic Aspects.] Thèse méd, Ouagadougou, 89 p.

[11] Ndjitoyap Ndam, E.C., Tzeuton, C., Mbakop, A., Pouepene, J., Guemne, T.A., Njoya, O., Tagni Sartre, M. and Ngu, L.J. (1990) Endoscopie digestive haute au Ca- 
meroun étude analytique de 4100 examens. [Ngu Upper Gastrointestinal Endoscopy in Cameroon Analytical Study of 4100 Examinations.] Medicine of Black Africa, 37, 453-456.

[12] Picardo, G.N. and Ajayi, A.N. (2015) Indications for an Endoscopic Findings in Patients with Symptoms of Upper Gastrointestinal Disease in a Tertiary Hospital in South-Eastern Nigeria. African Journal of Medical and Health Sciences, 14, 96-100. https://doi.org/10.4103/2384-5589.170169

[13] Redah, D., Konutse, A.Y., Agbo, K., Dogbey, E.H., Napo-Koura, G., Tchangai-Kao, S.T., Prince David, M., Amedegnato Mr., D. and Agbetra, A. (2001) Is Endoscopic Diagnosis of Candida Albicans Esophagitis Reliable? Correlations with Pathological and Mycological Examinations. Clinical and Biological Gastroenterology, 25, 161-163.

[14] Taye, M., Kassa, E., Mengesha, B., Gemechu, T. and Tsega, E. (2004) Upper Gastrointestinal Endoscopy: A Review of 10,000 Cells. Ethiopian Medical Journal, 42, 97-107.

[15] Traore, S.S., Sanou, J., Bonkoungou, G., Kirakoya, B., Zida, M., Bandre, E., et al. (1999) The Perforations of Peptic Ulcers at the National Yalgado Ouédraogo Hospital Center of Ouagadougou (Burkina Faso). CAMES Review, 1, 39-42.

[16] INSD (2014) Statistical Yearbook 2014. National Institute of Statistics and Demography (INSD), Ouagadougou.

[17] Poitras, P. (2016) The Digestive System: From the Basic Sciences to the Clinic. 2nd Edition, The University of Montreal Press, Montréal, 36.

[18] Aduful, H.K., Naaeder, S.B., Darko, R., Baako, B.N., Clegg-Lamptey, J.N.A., Nkrumah, K.N., Adu-Aryee, N.A. and Kyere, M. (2017) Upper Gastrointestinal Endoscopy at the Korle Bu Teaching Hospital in Accra, Ghana. Ghana Medical Journal, 41, 12-16.

[19] Tabiri, S., Akanbong, P. and Atiku, A. (2015) Upper Gastrointestinal Endoscopy Findings in Patients Presenting to Tamale Teaching Hospital, Ghana. Unified Journal of Medicine and Medical Sciences, 1, 2015-2250. http://www.unifiedjournals.org/ujmms

[20] Peghini, M., Rajaonarison, P., Pecarrere, J.L., Razafindrambaoa, H., Andriantsoavina, H., Rakotomalala, M. and Ramarokoto, N. (1996) Madagascar: Oesogastroduodenal Fibroscopy, Descriptive Analysis of 12000 Examinations and Problems Encountered in the Tropics. Medecine Tropicale (Mars), 56, 89-94.

[21] Olokoba, A.B. and Bojuwoye, B.J. (2010) Indications for Oesophagogastroduodenoscopy in Ilorin, Nigeria: A 30 Month Review. Nigerian Journal of Clinical Practice, 13, 260-263.

[22] Tunc, M., Boyuk, B. and Mavis, O. (2016) Upper GIS Endoscopy Indications of Patients Consulted at Internal Medicine Outpatient Clinics and Data Obtained According to These Indications. Open Journal of Gastroenterology, 6, 111-116. https://doi.org/10.4236/ojgas.2016.64015 